Research Paper

\title{
Energy and Nutritional Composition of Tiger Milk Mushroom (Lignosus tigris Chon S. Tan) Sclerotia and the Antioxidant Activity of Its Extracts
}

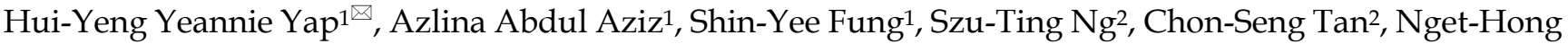 \\ $\operatorname{Tan}^{1}$
}

1. Department of Molecular Medicine, Faculty of Medicine, University of Malaya, 50603 Kuala Lumpur, Malaysia.

2. Ligno Biotech Sdn. Bhd., 43300 Balakong Jaya, Selangor, Malaysia.

\begin{abstract}
$\triangle$ Corresponding author: Hui-Yeng Yeannie Yap. Fax: +603 79675997; Phone: +603 79674912; Email address: yean_ny_nie@yahoo.com
( ) Ivyspring International Publisher. This is an open-access article distributed under the terms of the Creative Commons License (http://creativecommons.org/ licenses/by-nc-nd/3.0/). Reproduction is permitted for personal, noncommercial use, provided that the article is in whole, unmodified, and properly cited.
\end{abstract}

Received: 2013.12.11; Accepted: 2014.02.18; Published: 2014.04.12

\begin{abstract}
The Lignosus is a genus of fungi that have useful medicinal properties. In Southeast Asia, three species of Lignosus (locally known collectively as Tiger milk mushrooms) have been reported including $L$. tigris, $L$. rhinocerotis, and $L$. cameronensis. All three have been used as important medicinal mushrooms by the natives of Peninsular Malaysia. In this work, the nutritional composition and antioxidant activities of the wild type and a cultivated strain of $L$. tigris sclerotial extracts were investigated. The sclerotia are rich in carbohydrates with moderate amount of protein and low fat content. Free radical scavenging activities of $L$. tigris sclerotial extracts correlate with their phenolic content, which ranges from 6.25 to $45.42 \mathrm{mg} \mathrm{GAE} / \mathrm{g}$ extract. The FRAP values ranged from 0.002 to $0.041 \mathrm{mmol} / \mathrm{min} / \mathrm{g}$ extract, while the DPPH ${ }^{\circ}, \mathrm{ABTS}^{+}$, and superoxide anion (SOA) scavenging activities ranged from 0.18 to $2.53,0.01$ to 0.36 , and -4.53 to $10.05 \mathrm{mmol}$ Trolox equivalents $/ \mathrm{g}$ extract, respectively. L. tigris cultivar shows good prospect to be developed into functional food due to its good nutritional value and potent SOA scavenging activity.
\end{abstract}

Key words: Lignosus tigris, Tiger milk mushroom, nutrients, phenolics, antioxidants

\section{Introduction}

Mushrooms belonging to Lignosus, a genus of fungi of the family Polyporaceae, are highly valued for their medicinal properties. Their biopharmacological properties and functional food potentials have also been widely investigated. Known members of the genus include $L$. dimiticus, L. ekombitii, L. goetzii, $L$. hainanensis, L. rhinocerotis, and L. sacer. These mushrooms are found mainly in Africa, Southeast Asia, and Australia. The sclerotium is the part of the mushroom with beneficial biopharmacological properties and functional food potential. The sclerotial extract of $L$. rhinocerotis for instance, was found to have antihypertensive, anti-proliferative, immune-modulatory, and antioxidant activities [1-4]. The non-digestible carbohydrates isolated from Polyporus rhinocerus (synonym for L. rhinocerotis) sclerotium have also been found to be effective as novel prebiotic for gastrointestinal health [5].

Recently, Tan et al. [6] reported the discovery of a new species of Lignosus in Malaysia which is closely related to L. rhinocerotis. This new member of Lignosus was given the name L. tigris. Little is known about the properties of L. tigris, but it has often been mistaken for $L$. rhinocerotis due to their similarity in gross physical appearance, and hence, has also been consumed by the natives for medical benefits. Recent success in the cultivation of L. tigris in the laboratory enables large scale production of the mushroom sclerotia, and hence it is important to investigate its potential biopharmacological properties as well as nu- 
tritional composition; to evaluate whether this new species of mushroom can also be used as functional foods with beneficial biopharmacological properties.

Mushrooms are known for their nutritional values. Some mushrooms also contain considerable amount of antioxidants that may be beneficial medically. The naturally occurring antioxidant compounds found in mushrooms include phenolic compounds as well as other substances which can neutralize effectively free radicals and therefore may offer protection against oxidative stress-related diseases [6]. In this study, we investigated the nutritional composition and the various antioxidant properties of the sclerotial extracts of a wild type and a cultivated strain of $L$. tigris.

\section{Materials and methods}

\section{Materials}

Wild type L. tigris sclerotia were collected from the tropical forest in Lata Iskandar, central Peninsular Malaysia. Species identification was confirmed by sequence analysis of the rRNA gene internal transcribed spacer regions [7]. The cultivated strain of $L$. tigris (strain K) is the product of Ligno Biotech Sdn. Bhd. (Balakong Jaya, Malaysia). All reagents, chemicals, and standards were purchased from Sigma Aldrich (St. Louis, MO) unless otherwise stated. 3-(4,5-dimethylthiazol-2-yl)-2,5-diphenyltetrazolium bromide (MTT) was purchased from Merck \& Co. (Whitehouse Station, NJ). Methanol was purchased from Friendemann Schmidt Chemical (Parkwood, WA).

\section{Cell culture}

Human breast adenocarcinoma MCF7 (ATCC ${ }^{\circledR}$ HTB-22 $^{\mathrm{TM}}$ ) purchased from American Type Culture Collection (ATCC, Manassas, VA) was cultured in Roswell Park Memorial Institute (RPMI) 1640 (Lonza, Basel, Switzerland) supplemented with $10 \%$ fetal bovine serum. Penicillin-streptomycin of $1 \%$ was added during assays to prevent contamination. Cells were maintained in a humidified atmosphere of $5 \%$ $\mathrm{CO}_{2}$ at $37{ }^{\circ} \mathrm{C}$ and sub-culturing was performed every three to four days depending on the confluence state.

\section{Proximate analysis}

Crude protein content of sclerotial powder was determined by Kjedahl method with boric acid modification (AACC 46-12). The protein conversion factor used was 6.25. Fat and total ash contents were determined based on Sullivan and Carpenter [8]. Total sugar content was determined using AOAC 923.09 method. Soluble and insoluble dietary fibers were measured using AOAC 991.43 method. Total carbohydrates and energy content were calculated by dif- ference. Mineral concentrations were determined based on AOAC 984.27 method. Moisture content was assessed using air-oven method (AACC 44-15A). All AACC and AOAC standard protocols were performed according to AOAC International [9] and AACC International [10].

\section{Preparation of sclerotial extracts}

Extraction was carried out in a mass to volume ratio of 1:20 $(\mathrm{g} / \mathrm{mL})$, using freeze dried sieved sclerotial powder. Hot water extraction was carried out at 95 to $100{ }^{\circ} \mathrm{C}$ for $2 \mathrm{~h}$, cold water extraction was carried out at $4{ }^{\circ} \mathrm{C}$ for $24 \mathrm{~h}$, and methanol extraction was carried out by stirring at room temperature for $24 \mathrm{~h}$. Extraction mixture was then filtered through Whatman grade no. 1 filter paper. Water extracts were freeze dried and re-dissolved in Milli-Q water prior to analysis. Methanol extract was evaporated to dryness at $37{ }^{\circ} \mathrm{C}$ and re-dissolved in $10 \%$ dimethyl sulfoxide (DMSO).

\section{Antioxidant assays}

The antioxidant assays were adapted from our previous study [3]. Total phenolic content (TPC) was determined using Folin-Ciocalteau method [11]. Gallic acid from 10 to $200 \mu \mathrm{g} / \mathrm{mL}$ was used as standard for construction of the calibration curve and the phenolic content was expressed as mg gallic acid equivalents (GAE). Ferric reducing antioxidant power (FRAP) assay was performed according to Benzie and Strain [12]. 1,1-diphenyl-2-picrylhydrazyl (DPPH•) radical scavenging activity was measured according to Cos et al. [13]. 2,2-azinobis-3-ethylbenzothiazoline6-sulphonic acid (ABTS ${ }^{+}$) radical scavenging activity was determined according to Re et al. [14]. Superoxide anion (SOA) radical scavenging activity in the phenazine methoxysulfate (PMS)-NADH superoxide generating system was determined according to Siddhuraju and Becker [15]. Extracts were tested at concentration from 1 to $16 \mathrm{mg} / \mathrm{mL}$ in series of double dilution for FRAP, $\mathrm{DPPH}^{*}$, and $\mathrm{ABTS}^{*+}$ radical scavenging assays while for SOA radical scavenging assay, extracts were tested at concentration from 62.5 to $1000 \mu \mathrm{g} / \mathrm{mL}$ in series of double dilution. Trolox was used as standard for construction of the calibration curve for $\mathrm{DPPH}^{\cdot}, \mathrm{ABTS}^{*}$, and SOA radical scavenging assays and the results were expressed as mmol Trolox equivalents (TE). Quercetin and rutin served as positive controls for all assays.

\section{Cell-based SOA radical scavenging assay}

Monolayer MCF7 cells grown in 96-well plate were exposed to $0.625 \mathrm{U} / \mathrm{L}$ xanthine oxidase and 0.5 $\mathrm{mM}$ xanthine for $1 \mathrm{~h}$ in the presence of L. tigris extract from 2 to $125 \mu \mathrm{g} / \mathrm{mL}$ in series of double dilution. Re- 
action mixtures were then aspirated and cells were cultured in fresh growth medium for an additional 72 $\mathrm{h}$ prior to cell viability assessment by MTT assay. MTT solution $(5 \mathrm{mg} / \mathrm{mL}$ in phosphate buffered saline, PBS) was added subsequently at $20 \mu \mathrm{L}$ per well followed by additional incubation at $37^{\circ} \mathrm{C}$ for $4 \mathrm{~h}$ until purple formazan crystals developed. Total solutions were aspirated and DMSO $(200 \mu \mathrm{L}$ per well $)$ was added to dissolve the formazan. Absorbance at 570 $\mathrm{nm}$ was measured. Quercetin and rutin served as positive controls while PBS served as the negative control. The effects of L. tigris sclerotial extracts on the viability of MCF7 in relation to PBS was determined.

\section{Statistical analysis}

Results were expressed as mean \pm standard deviation (SD), unless otherwise stated. Statistical Package for the Social Sciences (SPSS) version 17.0 (SPSS Inc., Chicago, IL) with one-way ANOVA followed by the LSD's post hoc test for multiple comparisons was used to compare mean values. A $p$ value of less than 0.05 was considered as statistically significant.

\section{Results and discussion}

\section{Nutritional composition of L. tigris sclerotia}

Table 1 shows like L. rhinocerotis, the sclerotia of L. tigris are rich in carbohydrates with low fat content [3]. It is interesting to note that the carbohydrate composition of wild type L. tigris sclerotium differs from that of the cultivated L. tigris. The carbohydrate constituent of the wild type is made up mostly of insoluble fiber whilst the cultivated L. tigris has only a very small amount of soluble and insoluble fiber, as well as low amount of sugar. This suggests that much of the carbohydrate content of the cultivated L. tigris sclerotia is starch. Thus, the cultivated L. tigris sclerotium is a good source of dietary starch. In addition, the protein content and energy value of the cultivated L. tigris are almost two times more than the wild type; indicating that the sclerotium of L. tigris cultivar was superior to the wild type in overall nutritional content.

\section{Yield of extracts and phenolic content}

The yield of the various extracts from L. tigris cultivar was substantially higher than that of the wild type (Table 2). For the wild type, the yield of hot water and cold water extracts were comparable and far higher than the methanol extract. For the cultivated $L$. tigris, hot water extraction produced the highest yield (25 times that of wild type), followed by cold water extraction (12 times that of wild type). Although the yield of methanol extraction was only $12 \%$ of the hot water extract, it was three times more than hot or cold water extracts of the wild type. These show that the sclerotial powder of the cultivated L. tigris contains more water soluble substances of high polarity than the wild type. This finding is not surprising as $91.6 \%$ of the dry weight of wild type sclerotial powder was made up of insoluble fiber. The methanol extract presumably consists mainly the non-polar compounds of the sclerotium.

Table I. Energy value and nutrient composition of wild type and cultivated L. tigris sclerotia.

\begin{tabular}{lll}
\hline & Wild type & Cultivar \\
\hline Energy (kcal/100 g DW) & 204 & 385 \\
Crude protein (g/100 g DW) & 5.2 & 9.1 \\
Total fat (g/100 g DW) & $\mathrm{ND}(<0.1)$ & 2.0 \\
Total carbohydrate (g/100 g DW) & 91.6 & 84.4 \\
Dietary fiber (g/100 g DW) & 91.6 & 3.0 \\
- Insoluble fiber & 91.6 & 0.1 \\
- Soluble fiber & $\mathrm{ND}(<0.1)$ & 2.9 \\
Total sugar (g/100 g DW) & $\mathrm{ND}(<0.1)$ & 7.6 \\
Ash (g/100 g DW) & 1.1 & 0.5 \\
Moisture content (g/100 g DW) & 2.1 & 4.1 \\
Calcium, Ca (mg/100 g DW) & 5.0 & 26.3 \\
Magnesium, Mg (mg/100 g DW) & 85.4 & 40.5 \\
Potassium, K (mg/100 g DW) & 165 & 171 \\
Sodium, Na (mg/100 g DW) & 6.9 & 18.4 \\
\hline
\end{tabular}

Energy and nutritional composition of L. tigris sclerotia expressed on a dry weight (DW) basis. Abbreviation: ND, not detected.

Table 2. Yield and total phenolic content of $L$. tigris sclerotial extracts.

\begin{tabular}{|c|c|c|c|c|}
\hline & \multirow{2}{*}{$\begin{array}{l}\text { Solvent ex- } \\
\text { tract }\end{array}$} & \multirow{2}{*}{$\begin{array}{l}\text { Yield } \\
(\mathrm{mg} / \mathrm{g} \\
\mathrm{DW})\end{array}$} & \multicolumn{2}{|c|}{ Total phenolic content } \\
\hline & & & $\begin{array}{l}\text { mg GAE/g } \\
\text { extract }^{\mathrm{a}}\end{array}$ & $\begin{array}{l}\text { mg GAE/g } \\
\text { DWb }^{\mathrm{b}}\end{array}$ \\
\hline Wild & Hot water & 20 & $37.52 \pm 0.23^{c}$ & $0.75 \pm 0.00^{c}$ \\
\hline \multirow[t]{2}{*}{ type } & Cold water & 24 & $31.15 \pm 0.61^{d}$ & $0.74 \pm 0.00^{c}$ \\
\hline & Methanol & 4 & $45.42 \pm 0.35^{e}$ & $0.18 \pm 0.00^{\mathrm{d}}$ \\
\hline \multirow[t]{3}{*}{ Cultivar } & Hot water & 510 & $8.07 \pm 0.51^{\mathrm{f}}$ & $4.03 \pm 0.25^{\mathrm{e}}$ \\
\hline & Cold water & 290 & $12.17 \pm 0.10 \mathrm{~g}$ & $4.06 \pm 0.03 \mathrm{e}$ \\
\hline & Methanol & 61 & $6.25 \pm 0.18^{\mathrm{h}}$ & $0.39 \pm 0.01^{\mathrm{f}}$ \\
\hline
\end{tabular}

a Total phenolic content expressed as mg gallic acid equivalents (GAE) in $1 \mathrm{~g}$ extract. ${ }^{b}$ Total phenolic content expressed as mg gallic acid equivalents (GAE) in $1 \mathrm{~g}$ dry weight $(\mathrm{DW})$ mushroom. Values expressed as mean $\pm \mathrm{SD}(\mathrm{n}=3)$. Mean in the same column with different letters $(c-h)$ are significantly different $(p<0.05)$.

It is important to determine the content of phenolic secondary metabolites in the mushroom since antioxidant activity of most plant materials and fungi has been shown to be mostly due to the presence of their phenolic compounds [16]. Table 2 shows the total phenolic content of L. tigris extracts. Extracts from wild type have a higher content of phenolic compounds compared to the cultivar. However, when the values were expressed as dry weight of sclerotial powder (mg GAE/g DW), the amount of phenolic compounds was highest in L. tigris cultivar water extracts and lowest in the methanol extracts. For both the wild type and cultivar, the hot water extracts yielded the same amount of phenolic compounds as 
the cold water extracts indicating that the efficiency of extraction of phenolic compounds was not dependent on temperature of the extraction medium. It is interesting to note that the phenolic content of L. tigris cultivar water extracts was five times higher than that that of wild type.

\section{Antioxidant activity of $L$. tigris extracts}

Table 3 shows the ability of L. tigris extracts to reduce ferric ion and scavenge free radicals. In the ferric reducing assay, antioxidant activity of L. tigris was measured by its ability to reduce ferric-tripyridyltriazine $\left(\mathrm{Fe}^{3+}\right.$-TPTZ) to ferrous complex ( $\left.\mathrm{Fe}^{2+}-\mathrm{TPTZ}\right)$. FRAP value of all extracts were rather low in comparison to the positive controls, but were similar to that reported for Mexican mushrooms [17].

The efficiency of antioxidants to prevent oxidative damage and inhibit lipid peroxidation is dependent on their free radical scavenging ability. $\mathrm{DPPH}^{*}, \mathrm{ABTS}^{\cdot+}$, and SOA radical scavenging activities were determined by comparing the percentage inhibition of free radicals by L. tigris extracts to Trolox in terms of Trolox equivalent antioxidant capacity (TEAC) (Table 3). Inhibition of the free radicals was dose-dependent. DPPH ${ }^{\bullet}$ radical scavenging activity was tested in L. tigris extracts at a concentration range of 1 to $16 \mathrm{mg} / \mathrm{mL}$ and concentrations that caused $50 \%$ inhibition of radicals ( $\mathrm{IC}_{50}$ values) were estimated from the dose-response curve. Wild type methanol extract has the lowest $\mathrm{IC}_{50}(1.0 \mathrm{mg} / \mathrm{mL})$, followed by wild type hot water extract $(2.9 \mathrm{mg} / \mathrm{mL})$, cultivar cold water extract $(3.3 \mathrm{mg} / \mathrm{mL})$ and wild type cold water extract $(3.6 \mathrm{mg} / \mathrm{mL})$. The $\mathrm{IC}_{50}$ values for the cultivar hot water and methanol extracts were greater than 16 $\mathrm{mg} / \mathrm{mL}$. When compared with other related Polyporales, the $\mathrm{IC}_{50}$ values for most of the L. tigris extracts were comparable to those of L. rhinocerotis but lower than those of Ganoderma lucidum [3, 18].

When reacted with $\mathrm{ABTS}^{\bullet+}$, the methanol extract of wild type L. tigris showed the highest scavenging activities, presumably owing to its high phenolic content. The hot water and cold water extracts of the wild type L. tigris exhibited slightly lower scavenging activities, while all three extracts of the cultivar showed rather weak activities when compared to the positive controls.

Another important free radical scavenging activity in plant and fungus is SOA scavenging activity. Superoxides are continuously produced in all living organisms during metabolic processes and are biologically toxic to their cellular components. Excessive generation of SOA plays important role in carcinogenesis and induces pro-inflammatory state in many diseases $[19,20]$. SOA scavenging activity of L. tigris extracts as measured by the PMS-NADH superoxide generating system demonstrated a considerably strong dose-response inhibition of the SOA radicals at concentrations below $1 \mathrm{mg} / \mathrm{mL}$. When expressed as TEAC, the hot water extract of wild type L. tigris exhibited the highest activity $(10.05 \pm 0.08 \mathrm{mmol} \mathrm{TE} / \mathrm{g}$ extract); a level which was higher than rutin (9.62 \pm $0.07 \mathrm{mmol} \mathrm{TE} / \mathrm{g}$ extract). Other extracts of both the wild type and cultivar of L. tigris also exhibited considerable SOA scavenging activities (except for methanol extract of the cultivar). The high SOA scavenging activity of the L. tigris extracts in contrast to their lower ferric reducing, $\mathrm{DPPH}^{*}$, and ABTS ${ }^{*+}$ radical scavenging activities suggests that in addition to their phenolic content, other non-phenolic compounds may be present in the extracts with the ability to scavenge SOA. Negative inhibition was observed in the methanol extract of L. tigris cultivar at concentrations above $500 \mu \mathrm{g} / \mathrm{mL}$, this phenomenon was also seen in our previous study on L. rhinocerotis as well as in marine macroalgae [3, 21]. Overall, the free radical scavenging activities of $\mathrm{L}$. tigris extracts correlated well with their phenolic content (mg GAE/g extract). The wild type extracts were more potent in free radical scavenging activities, the same phenomenon was also observed in the closely related species L. rhinocerotis where the wild type sclerotial extracts also exhibited higher antioxidant activities than the cultivated strain [3].

Table 3. Antioxidant activities of $L$. tigris sclerotial extracts.

\begin{tabular}{|c|c|c|c|c|c|}
\hline & & \multirow[t]{2}{*}{ FRAP value } & \multicolumn{3}{|c|}{ Trolox equivalent antioxidant capacity (TEAC, mmol TE/g extract) } \\
\hline & & & DPPH• & $\mathrm{ABTS}^{\bullet+}$ & SOA \\
\hline \multirow[t]{3}{*}{ Wild type } & HWE & $0.018 \pm 0.00^{\mathrm{a}}$ & $1.01 \pm 0.05^{\mathrm{a}}$ & $0.25 \pm 0.02^{\mathrm{a}}$ & $10.05 \pm 0.08^{\mathrm{a}}$ \\
\hline & CWE & $0.014 \pm 0.00^{\mathrm{b}}$ & $0.79 \pm 0.05^{\mathrm{b}}$ & $0.27 \pm 0.00^{\mathrm{b}}$ & $8.53 \pm 0.04^{\mathrm{b}}$ \\
\hline & ME & $0.041 \pm 0.00^{c}$ & $2.53 \pm 0.07 \mathrm{c}$ & $0.36 \pm 0.01^{\mathrm{c}}$ & $8.80 \pm 0.10^{c}$ \\
\hline \multirow[t]{3}{*}{ Cultivar } & HWE & $0.002 \pm 0.00^{\mathrm{d}}$ & $0.19 \pm 0.01^{\mathrm{d}}$ & $0.01 \pm 0.02^{\mathrm{d}}$ & $4.82 \pm 0.16^{\mathrm{d}}$ \\
\hline & CWE & $0.014 \pm 0.00^{\mathrm{b}}$ & $0.45 \pm 0.03 \mathrm{e}$ & $0.09 \pm 0.03 \mathrm{e}$ & $7.98 \pm 0.07 \mathrm{e}$ \\
\hline & ME & $0.002 \pm 0.00^{d}$ & $0.18 \pm 0.02^{\mathrm{d}}$ & $0.04 \pm 0.02^{\mathrm{d}}$ & $-4.53 \pm 0.18^{f}$ \\
\hline Quercetin & & $3.378 \pm 0.15^{\mathrm{e}}$ & $4.83 \pm 0.02^{\mathrm{f}}$ & $2.00 \pm 0.00^{\mathrm{f}}$ & $11.43 \pm 0.10 \mathrm{~g}$ \\
\hline Rutin & & $0.572 \pm 0.04^{\mathrm{f}}$ & $4.85 \pm 0.00^{\mathrm{f}}$ & $1.64 \pm 0.00 \mathrm{~g}$ & $9.62 \pm 0.07 \mathrm{~h}$ \\
\hline
\end{tabular}

Antioxidant activities expressed as mean \pm SD $(\mathrm{n}=3)$. FRAP value expressed in $\mathrm{mmol} / \mathrm{min} / \mathrm{g}$ extract. Mean in the same column with different letters $(\mathrm{a}-\mathrm{h})$ are significantly different $(p<0.05)$. Abbreviations: TE, Trolox equivalents; HWE, hot water extract; CWE, cold water extract; ME, methanol extract; SOA, superoxide anion. 

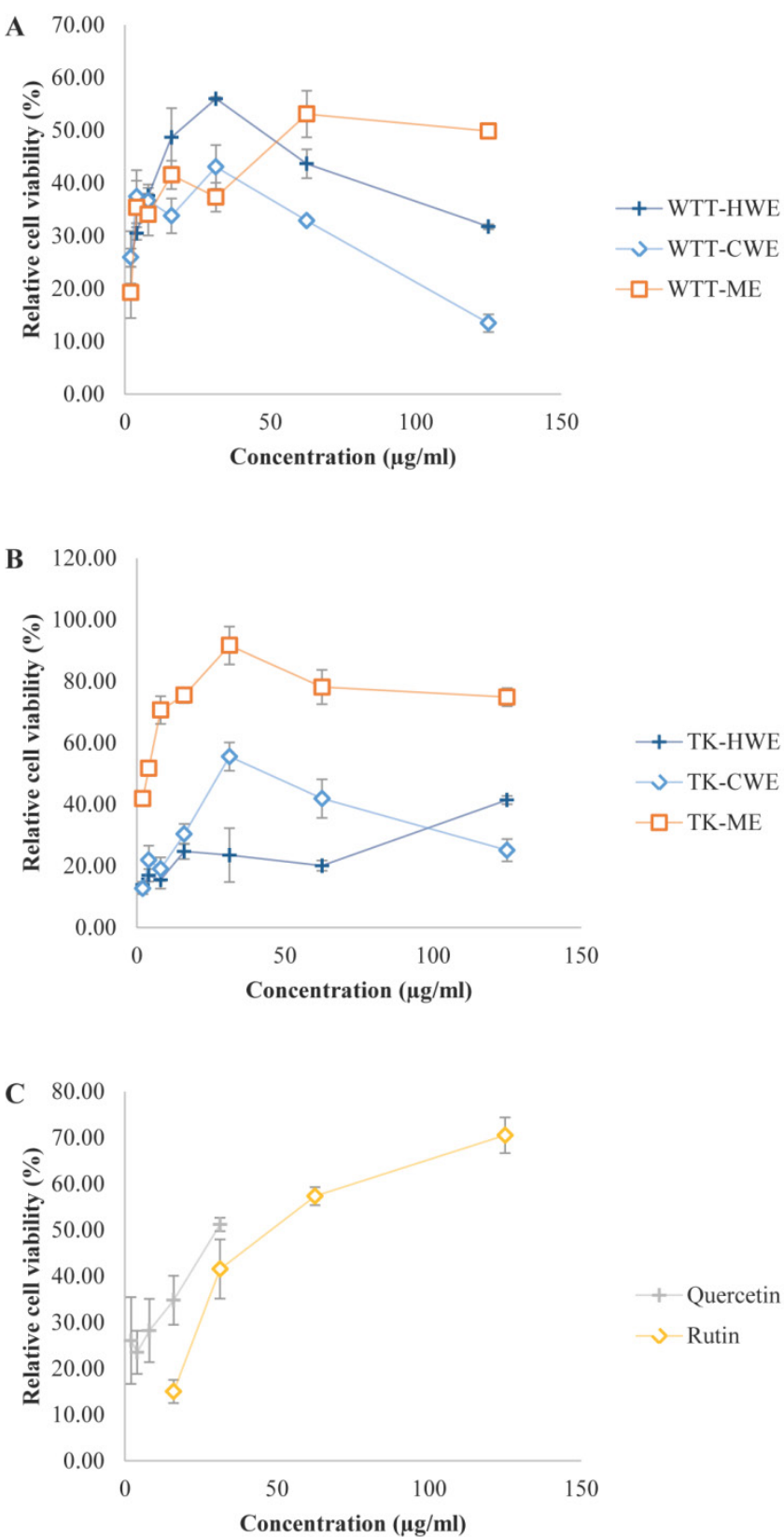

Figure I. Superoxide anion (SOA) radical scavenging activity of L. tigris extracts in a cell based system. Xanthine/xanthine oxidase system was used to generate exogenous SOA radical and the abilities of various $L$. tigris extracts to protect the MCF7 cells against the cytotoxic action of the generated superoxides were determined by measuring the relative cell viability (\% viability). Data expressed as mean $\pm S D(n=3)$. (A) Wild type L. tigris (abbreviated as WTT); (B) L. tigris cultivar (abbreviated as TK, TK stands for L. tigris strain K); (C) positive controls (quercetin and rutin). Other abbreviations: HWE, hot water extract; CWE, cold water extract; ME, methanol extract.

In order to assess the efficacy and potential of $L$. tigris as a SOA scavenger in cellular system, we also examined the SOA inhibitory activity of the extracts using an in vitro cell-based model. In this model, xanthine/ xanthine oxidase (XOD) system was used to generate exogenous SOA and the ability of the extracts to protect MCF7 cells against the cytotoxic action of the generated SOA was then examined (Figure
1). It is interesting to find that the extracts exhibited more potent SOA scavenging capacity in the cell-based system than in the non-cell-based PMS-NADH system. This was presumably due to the differences in the way the SOA were generated. In addition, the tumorigenic MCF7 cells may be more sensitive to the action of SOA generated. Xanthine and xanthine oxidase were not cytotoxic on their own at the concentrations used in the experiment, but the XOD system induced 75 to $85 \%$ cytotoxicity to MCF7. It has been established that quercetin, rutin, and the $L$. tigris extracts by themselves were not cytotoxic at their tested concentrations. In general, L. tigris cultivar extracts exhibited promising SOA scavenging capacity in the cell-based assay model in a dose-dependent manner. The lowest $\mathrm{IC}_{50}$ value was obtained with the cultivar methanol extract $(4 \mu \mathrm{g} / \mathrm{mL})$. This was followed by wild type hot water extract $(18 \mu \mathrm{g} / \mathrm{mL})$, cultivar cold water extract $(28 \mu \mathrm{g} / \mathrm{mL})$, and wild type methanol extract $(56 \mu \mathrm{g} / \mathrm{mL})$. These $\mathrm{IC}_{50}$ values are comparable or lower than the positive controls including quercetin $\left(\mathrm{IC}_{50}=30 \mu \mathrm{g} / \mathrm{mL}\right)$ and rutin $\left(\mathrm{IC}_{50}=\right.$ $47 \mu \mathrm{g} / \mathrm{mL}$ ); implying the extracts exhibited potent radical scavenging abilities. However, reduction in the SOA scavenging capacity was observed in wild type hot water and cold water extracts as well as in cultivar cold water extract at concentration higher than $31.25 \mu \mathrm{g} / \mathrm{mL}$. This is presumably due to a concentration-dependent biphasic effect which was also observed in the PMS-NADH system, as discussed earlier.

\section{Conclusion}

To the best of our knowledge, this is the first report on the potential health benefits of $L$. tigris sclerotia, in particular its nutritional content and antioxidant activities of its extracts. In term of nutritional content, the cultivar of L. tigris was superior than the wild type. In term of antioxidant activities, however, the wild type L. tigris extracts were more potent. The potential of the wild type L. tigris sclerotia to be developed as a functional food, however, is constrained by its rarity in nature and the low extraction yield. In view of the high nutritional content, higher total antioxidant activity in the sclerotial extracts, $L$. tigris cultivar, which can be cultivated in large scale, has greater potential to be developed as functional food and nutraceutical.

\section{Acknowledgement}

This research is supported by Postgraduate Research Fund (PPP) PV024/2012A from the University of Malaya, Malaysia. 


\section{Competing Interests}

The authors have declared that no competing interest exists.

\section{References}

1. Lee ML, Tan NH, Fung SY, Tan CS, Ng ST. The antiproliferative activity of sclerotia of Lignosus rhinocerus (Tiger Milk Mushroom). Evid Based Complement Alternat Med. 2012; 2012: 697603.

2. Wong K-H, Lai CKM, Cheung PCK. Immunomodulatory activities of mushroom sclerotial polysaccharides. Food Hydrocoll. 2011; 25: 150-8.

3. Yap YH, Tan N, Fung S, Aziz AA, Tan C, Ng S. Nutrient composition, antioxidant properties, and anti-proliferative activity of Lignosus rhinocerus Cooke sclerotium. J Sci Food Agric. 2013; 93: 2945-52.

4. Lai CKM, Wong K-H, Cheung PCK. Antiproliferative effects of sclerotial polysaccharides from Polyporus rhinocerus Cooke (Aphyllophoromycetideae) on different kinds of leukemic cells. Int J Med Mushrooms. 2008; 10: 255-64.

5. Gao S, Lai CKM, Cheung PCK. Nondigestible carbohydrates isolated from medicinal mushroom sclerotia as novel prebiotics. Int J Med Mushrooms. 2009; 11: 1-8.

6. Tan CS, Ng ST, Tan J. Two new species of Lignosus (Polyporaceae) from Malaysia - L. tigris and L. cameronensis. Mycotaxon. 2013; 123: 193-204.

7. Ferreira IC, Barros L, Abreu RM. Antioxidants in wild mushrooms. Curr Med Chem. 2009; 16: 1543-60.

8. Sullivan DM, Carpenter DE. Methods of analysis for nutrition labeling. Maryland, USA: AOAC International; 1993.

9. AOAC International. Official Method of Analysis of AOAC International (16th edn). Virginia, USA: Association of Official Analytical Communities; 1995.

10. [Internet] AACC International. http://methods.aaccnet.org/toc.aspx

11. Singleton VL, Rossi JA. Colorimetry of total phenolics with phosphomolybdic-phosphotungstic acid reagents. Am J Enol Vitic. 1965; 16: 144-58.

12. Benzie IF, Strain JJ. The ferric reducing ability of plasma (FRAP) as a measure of "antioxidant power": the FRAP assay. Anal Biochem. 1996; 239: 70-6.

13. Cos P, Rajan P, Vedernikova I, Calomme M, Pieters L, Vlietinck AJ, et al. In vitro antioxidant profile of phenolic acid derivatives. Free Radic Res. 2002; 36: 711-6.

14. Re R, Pellegrini N, Proteggente A, Pannala A, Yang M, Rice-Evans C. Antioxidant activity applying an improved ABTS radical cation decolorization assay. Free Radic Biol Med. 1999; 26: 1231-7.

15. Siddhuraju $P$, Becker $K$. The antioxidant and free radical scavenging activities of processed cowpea (Vigna unguiculata (L.) Walp.) seed extracts. Food Chem. 2007; 101: 10-9.

16. Velioglu YS, Mazza G, Gao L, Oomah BD. Antioxidant activity and total phenolics in selected fruits, vegetables, and grain products. J Agric Food Chem. 1998; 46: 4113-7.

17. Alvarez-Parrilla E, de la Rosa LA, Martínez NR, González GAA. Total phenols and antioxidant activity of commercial and wild mushrooms from Chihuahua, Mexico. Cienciay Tecnol Aliment. 2007; 5: 329-34.

18. Abdullah N, Ismail SM, Aminudin N, Shuib AS, Lau BF. Evaluation of selected culinary-medicinal mushrooms for antioxidant and ACE inhibitory activities. Evid Based Complement Alternat Med. 2012; 2012: 464238.

19. $\mathrm{Li} \mathrm{C}$, Zhou HM. The role of manganese superoxide dismutase in inflammation defense. Enzyme res. 2011; 2011: 387176.

20. Lopez-Lazaro M. Excessive superoxide anion generation plays a key role in carcinogenesis. Int J Cancer. 2007; 120: 1378-80.

21. Zubia M, Robledo D, Freile-Pelegrin Y. Antioxidant activities in tropical marine macroalgae from the Yucatan Peninsula, Mexico. J Appl Phycol. 2007; 19: 449-58. 